\title{
Coyote multi-objective optimization algorithm for optimal location and sizing of renewable distributed generators
}

\author{
E. M. Abdallah ${ }^{1}$, M. I. Elsayed ${ }^{2}$, M. M. ELgazzer ${ }^{3}$, Amal A. Hassan ${ }^{4}$ \\ 1,2,3 Department of Electrical and Machines, Faculty of Engineering, Al-Azhar University, Egypt \\ ${ }^{4}$ Electronics Research Institute, Cairo, Egypt
}

\begin{tabular}{l} 
Article Info \\
\hline Article history: \\
Received Feb 17, 2020 \\
Revised Aug 14, 2020 \\
Accepted Sep 30, 2020 \\
\hline Keywords: \\
Coyote optimization algorithm \\
renewable energy \\
Distributed generators \\
Power loss reduction \\
Voltage stability index
\end{tabular}

Corresponding Author:

E. M. Abdallah

Department of Electrical and Machines, Faculty of Engineering

Al-Azhar University

Nasr City, Cairo, Egypt

Email: eng.eman1928@yahoo.com

\begin{abstract}
Research on the integration of renewable distributed generators (RDGs) in radial distribution systems (RDS) is increased to satisfy the growing load demand, reducing power losses, enhancing voltage profile, and voltage stability index (VSI) of distribution network. This paper presents the application of a new algorithm called 'coyote optimization algorithm (COA)' to obtain the optimal location and size of RDGs in RDS at different power factors. The objectives are minimization of power losses, enhancement of voltage stability index, and reduction total operation cost. A detailed performance analysis is implemented on IEEE 33 bus and IEEE 69 bus to demonstrate the effectiveness of the proposed algorithm. The results are found to be in a very good agreement.
\end{abstract}

This is an open access article under the CC BY-SA license.

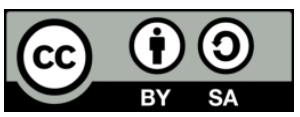

\section{INTRODUCTION}

Generally, the electrical distribution network (DN) is the final stage for electrical connection between the enormous power supply and the electricity users. The DN is a complex system and it is characterized by high power losses due to high $(\mathrm{R} / \mathrm{X})$ ratio [1]. To overcome this problem many researches are performed on the integration of distributed generators (DGs) in DN [2]. DGs known as a small scale electrical generation unit (typically $1 \mathrm{~kW}-50 \mathrm{MW}$ ) it is located near to load side. DGs may depend on conventional and/or non-conventional sources. Renewable energy power generation is increasing rapidly. Solar and wind resources are the most readily available sources. Also, DGs plays significant role in decreasing power losses, enhancing voltage stability and voltage profile of all busses [3]. In order To benefit from installation DGs in DN; placement and size of DGs must be optimized Considering DGs capacity and voltage limit. The inappropriate siting and sizing of DG units in the RDS will adversely affect the system, which is increased power loss and voltage instability [4]. Thus, several research has been done to evaluate the advantages of integration RDGs on DN by optimally sizing and placing for these unites through solving a single or several objectives problems. Many algorithms are used to solve this problem to enhance the performance of electrical DN. In [5], performance improvement of distribution systems is proposed by solving multi-objective functions using the genetic algorithm (GA). In [6], an approach is presented for optimum DGs siting to enhance voltage stability for all buses of network and less power losses. In [7], genetic and particle swarm optimization are implemented to find the optimum size and location of DGs to reduce power losses and to enhance voltage regulation and voltage stability of DN. In [8], multi-objective 
optimization is proposed to find optimal sizing and placement of DGs using Pareto frontier differential evolution algorithm. In [9] a strategy for programming goals using GA was proposed for solving a multiobjective DGs planning in distribution power system. In [10], firefly algorithm is implemented to obtain an optimal siting of multiple DGs in the DN. Some researches take into account the economical perspectives of DGs allocation problems such as in [11] that presented optimal sizing and placement of DGs for reducing power losses and total investment cost using probabilistic multi-objective optimization algorithm. In [12], RDGs are integrated into a distribution system for power losses reduction using a honey bee mating optimization algorithm.

This paper introduce application of new effective algorithm called "coyote optimization algorithm (COA)" to find the optimal size and location of DGs based renewable energy by solving multi-objective function. The objectives are minimizing power losses, enhancement of VSI for all buses of network, and decreasing the total operation cost at constant load power. By solving these objectives, the performance of electrical networks will be improved. Two types of DGs are used; type I deliver active power only like photovoltaic and type II deliver active and reactive power at different power factors 0.95 and 0.85 such as wind turbine. The proposed COA algorithm is implemented on the IEEE RDS including IEEE 33 bus and IEEE 69 bus. COA algorithm gives better results compared to other algorithms.

\section{PROBLEM FORMULATION}

\subsection{Power flow analysis}

In RDS Power flow and voltage corresponding to each bus can be calculated using forwardbackward sweep algorithm [13], a single line diagram of the sample RDS is shown in Figure 1.

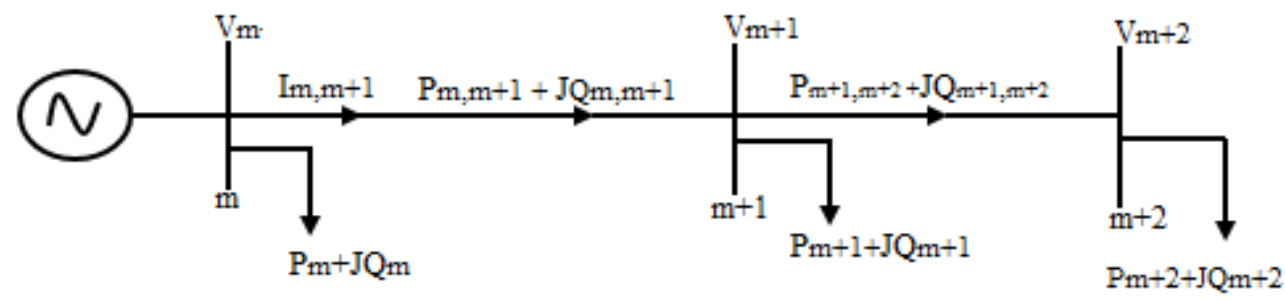

Figure 1. Single line diagram of the sample RDS

From Figure 1, the injected current at node $\mathrm{m}$ is calculated from:

$$
\mathrm{I}_{\mathrm{m}}=\left(\frac{\mathrm{P}_{\mathrm{m}}+\mathrm{jQm}}{\mathrm{V}_{\mathrm{m}}}\right)^{*}
$$

The voltage at bus $m+1$ can be determine as in (2):

$$
\mathrm{V}_{\mathrm{m}+1}=\mathrm{V}_{\mathrm{m}}-\mathrm{I}_{\mathrm{m}, \mathrm{m}+1} *\left(\mathrm{R}_{\mathrm{mm}+1}+\mathrm{j} \mathrm{X}_{\mathrm{m}, \mathrm{m}+1}\right)
$$

The branch current between bus $\mathrm{m}$ and bus $\mathrm{m}+1$ is determined as follow:

$$
\mathrm{I}_{\mathrm{m}, \mathrm{m}+1}=\mathrm{I}_{\mathrm{m}+1}+\mathrm{I}_{\mathrm{m}+2}
$$

Power loss in line section between buses $\mathrm{m}$ and $\mathrm{m}+1$ is determined as follow:

$$
\operatorname{Ploss}_{m, m+1}=R_{m, m+1} *\left(\frac{P_{m, m+1}{ }^{2}+j Q_{m, m+1}{ }^{2}}{V_{m}^{2}}\right)
$$

The network total power losses can be calculated through summing losses in all branches of the network which is given as:

$$
P_{\text {total losses }}=\sum_{m=1}^{b} \text { Ploss }_{m, m+1}
$$

where $\mathrm{b}$ is total number of branches 


\subsection{Power loss minimization}

After DGs installation at an optimal location, the power losses will be decrees and the voltage stability index will be enhanced. The power losses for the line section between buses $\mathrm{m}$ and $\mathrm{m}+1 \mathrm{can}$ be determine as written in (6) [14].

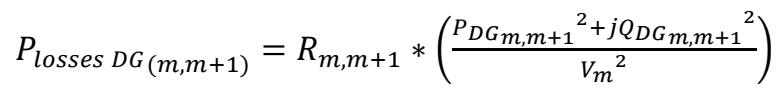

After DGs installation, the total power loss is determined as follows:

$$
P_{D G_{\text {total losses }}}=\sum_{m=1}^{b} \operatorname{Ploss}_{D G_{m, m+1}}
$$

Power loss index (PLI) can be determined as given in [15]:

$$
f_{1}=P L I=\frac{P_{D G_{\text {total losses }}}}{P_{\text {total losses }}}
$$

where: $P_{D G}$ total losses is total power loss if there is DGs.

$P_{\text {total losses }}$ is total power loss in absence of DGs.

By installation DGs in RDS the power losses can be minimize, so PLI will be minimized.

\subsection{Voltage stability index (VSI) improvement}

It is extremely necessary to maintain the $\mathrm{DN}$ in stable operation under heavy load conditions, so it is important to calculate VSI as shown in (9) [16].

$$
V S I_{i}=\left|V_{J}\right|^{4}-4 *\left[P_{i}(i) R_{i j}+Q_{i}(i) X_{i j}\right]\left|V_{J}\right|^{2}-4 *\left|P_{i}(i) R_{i j}+Q_{i}(i) X_{i j}\right|^{2}
$$

where $P_{i}$, is load active power at bus $i$, and $Q_{i}$ is load reactive power bus $i, R_{i j}$ and $X_{i j}$ are the resistance and reactance of branch $i j$.

The bus which has a minimum value of VSI is the most sensetivity bus to voltage collapse under increasing load these lead to instability of the voltage. To maintain the system operation in a stable limit, it is required to maintain VSI at a higher value. As shown in (10) shows the objective function for improving VSI:

$$
f_{2}=\min 1 / V S I
$$

\subsection{Operation cost minimization}

One of the benefits of optimum allocation and sizing of DGs in the DN is minimizing overall operating costs. The total operation cost (TOC) comprises two element ; the first element is cost of the real active power drawn from electrical substation that reduced by reducing the total power losses and the second element is cost of active power drown from the DGs which can be minimized by minimizing DGS size [17]:

$$
\mathrm{TOC}=\left(X_{1} P_{D G \text { total losses }}\right)+\left(X_{2} P_{D G T}\right)
$$

where $X_{1}$ and $X_{2}$ are active power cost coefficient in $\$ / \mathrm{KW}$ supplied from substation and DGs. The net operation cost can be calculated as:

$$
f_{3}=\triangle O C=\frac{T O C}{X_{2} P_{D G T} \operatorname{Max}}
$$

The TOC will be minimized by minimizing net operation costs.

\subsection{Formulation of multi-objective function and constraints}

The proposed objective functions aim to minimize power losses, TOC and maximize VSI as shown in (13).

$$
\operatorname{minimize} \mathrm{OF}=\min \left(w_{1} f_{1}+w_{2} f_{2}+w_{3} f_{3}\right)
$$

where,

$$
w_{1}+w_{2}+w_{3}=1
$$


where $w$ is the weight factor and its value is chosen corresponding to the importance of power losses, voltage stability index, and operation cost. The minimization of objective functions must satisfy the operation and planning constraints to meet the electrical power system requirement. These constraints are presented as follows:

Power balance constraint:

$$
\sum_{m=2}^{n} P_{g m}=\sum_{m=2}^{n} P_{d m}+\sum_{m=1}^{b} \text { Ploss }_{m, m+1}
$$

where: $\mathrm{n}$ is total number of buses

$$
\sum_{m=2}^{n} Q_{g m}=\sum_{m=2}^{n} Q_{d m}+\sum_{m=1}^{b} Q_{\text {losses }}
$$

Bus voltage limit:

$$
\left|V_{m}{ }^{\text {Min }}\right| \leq\left|V_{m}\right| \leq\left|V_{m}^{\text {Max }}\right|
$$

where $\left|V_{m}{ }^{\text {Min }}\right|$ and $\left|V_{m}{ }^{\text {Max }}\right|$ is the lower and upper bounder of the voltage $\left|V_{m}\right|$

$$
\left|V_{m}{ }^{M i n}\right|=0.95 p u \text { and }\left|V_{m}{ }^{M a x}\right|=1.05 p u
$$

Thermal limits:

$$
\mathrm{I}_{(\mathrm{m}, \mathrm{m}+1)} \leq \mathrm{I}_{(\mathrm{m}, \mathrm{m}+1) \mathrm{Max}}
$$

DGs capacity limits:

$$
P_{D G T}^{\text {Min }} \leq P_{D G T} \leq P_{D G T}^{\text {Max }}
$$

where,

$$
P_{D G T}{ }^{\text {Min }}=0.1 * \sum_{m=1}^{n} P_{d m} \quad \& \quad P_{D G T}{ }^{\text {Max }}=0.6 * \sum_{m=1}^{n} P_{d m}
$$

The resultant solution will be accepted if all the above constraints satisfied otherwise it should be rejected.

\section{COYOTE OPTIMIZATION ALGORITHM (COA)}

The proposed (COA) population focused on the coyote's behavior, Canis latrans species identified as swarm intelligence and evolutionary heuristic species $[18,19]$. Coyote population classified into $N p \in \mathrm{N} *$ packs with $N c \in \mathrm{N} *$ coyotes each. The total algorithm population is determined by $N p$ and $N c$ multiplication. For optimization problem each coyote is a potential solution and its social status is the cost of the objective function [20].

\subsection{Algorithm steps}

- Initialization

In COA the first step is initializing global coyote population as written in (22):

$$
\operatorname{soc}_{c j}^{p, t}=l p_{j}+r_{j} *\left(u b_{j}+l b_{j}\right)
$$

where, $l b j$ is the lower boundary , $u b j$ is upper boundary of the $j^{\text {th }}$ decision variable, $D$ is defined as the search space and $r_{j}$ is a real random number generated within the range $[0,1]$.

- Verify the adaptation of the coyote according to (23):

$$
\mathrm{fit}_{c}{ }^{p, t}=f\left(\operatorname{soc}_{c}{ }^{p, t}\right)
$$

- Defines the pack's Alpha coyote

The $\mathrm{p}^{\text {th }}$ pack alpha coyote in the $\mathrm{t}^{\text {th }}$ instant of time is determined as in (24):

$$
\operatorname{alpha}^{p, t}=\left\{\operatorname{soc}_{C}^{p t} \mid \arg _{c}=\{1,2, \ldots \ldots \ldots, N C\} \operatorname{minf}\left(\operatorname{soc}_{C}^{p, t}\right)\right\}
$$

- Calculate the pack 's social tendencies 
- Update Coyote's social condition equation:

Using alpha and pack affect the social condition of coyote can be obtained through the following

$$
\operatorname{newsoc}_{C}^{p, t}{ }_{C}=\operatorname{soc}^{p, t}{ }_{C}+r_{1} * \delta_{1}+r_{2} * \delta_{2}
$$

where, $r_{1}$ is weight of the alpha,$r_{2}$ is weight of pack influence., $r_{1}$ and $r_{2}$ are random numbers with in the generated range $[0,1]$.

- Evaluating new social condition:

$$
\text { new } \text { it }_{C}^{p, t}=f\left(\text { newsoc }_{C}{ }_{C}\right)
$$

- Adaptation

Adaptation means maintaining the new social condition better than the old one as in (27):

$$
\operatorname{soc}^{p, t+1}{ }_{C}=\left\{\begin{array}{cc}
\text { newsoc }{ }^{p, t}{ }_{C}, & \text { new } f i{ }^{p, t}{ }_{C}<\text { fit }^{p, t}{ }_{C} \\
\operatorname{soc}^{p, t}{ }_{C} & \text { other wise }
\end{array}\right\}
$$

- Transition between packs

Sometimes the coyotes abandon their packs and become lonely or join in a pack. The possibility of leaving coyote its back will be:

$$
P_{e}=.005 * N^{2}{ }_{C}
$$

number of coyotes per pack is restricted to 14 , given that Pe may expect values higher than 1 for $N c$ $\leq \sqrt{ } 200$ diversify interaction of all population's coyotes, meaning cultural exchange among the global population.

- Update the coyotes' ages.

- Select the most adapted coyote (best size and location).

The flowchart of COA for optimal location and size of DG is shown in Figure 2.

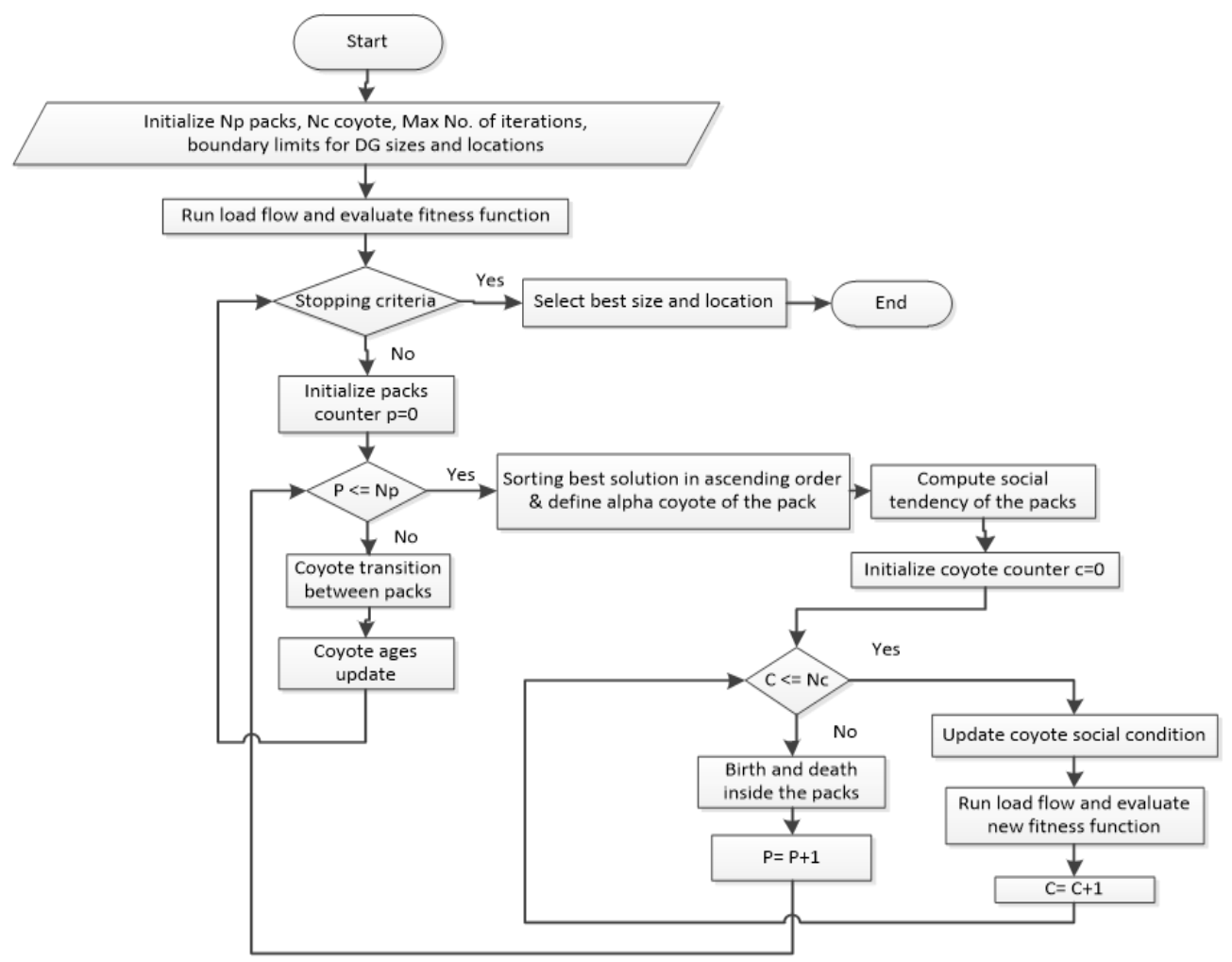

Figure 2. Flowchart of COA for optimal location and size of DGs 


\section{SIMULATION RESULTS AND DISCUSSION}

Two distribution systems are used to verify the effectiveness of the COA; IEEE 33 bus and IEEE 69 bus. The objective functions are to minimize PLI and TOC and maximize VSI. For multi-objective optimization highly importance are given to power loss, VSI and TOC, respectively, according to weight factors $\mathrm{W}_{1}, \mathrm{~W}_{2}$ and $\mathrm{W}_{3}$ which are taken as $0.5,0.4,0.1$, respectively, $X_{1}$ and $X_{2}$ are the cost coefficient and taken for the test systems as $4 \$ / \mathrm{kW}$ and $5 \$ / \mathrm{kW}$ respectively.$X_{2}$ is slightly higher than $X_{1}$ because it includes the installation and maintenance cost of DGS [17]. The proposed algorithm is implemented for two types of RDGs (PV \& wind turbine) at different power factors. In the simulation, the load model is considered as a constant load power $(\mathrm{CP})$. The proposed method is implemented using MATLAB 16 software running on a computer with Intel®_Core_i7 CPU @ $2.4 \mathrm{GHz}$ and 8 GB of RAM.

\subsection{Optimization results for IEEE 33 bus}

The first test system is the IEEE 33 bus that has a total load of $3.72 \mathrm{MW}$ and 2.3 MVAr at voltage 12.66 KV [21]. Forward-backward sweep algorithm is used to determine total power losses for base case which is $202.6771 \mathrm{KW}$ with minimum voltage $0.9131 \mathrm{p} . \mathrm{u}$ at bus 18 . Optimization results are presented in Table 1. It is clear that the percentage of power loss reduction is increased; VSI and voltage profile are more enhanced when installation DGs operate at $0.85 \mathrm{pf}$. This means that the reactive power substantially effect on power losses minimization and improving voltage profile and voltage stability index. Simulation results obtained by COA are compared with results obtained from numerous other algorithms previously published such as GA, PSO, FA, and SA to prove the effectiveness of the proposed algorithm. Comparison results are tabulated in Table 2 (see in appendix). It is clear from the comparison table that COA gives a good agreement in case of power loss reduction. Moreover, in the case of VSI and voltage profile improvement, COA gives better results than other algorithms for DGs size at the same range. For $0.95 \mathrm{pf}$, COA gives better results regarding the voltage profile and VSI as indicated in Table 2 (see in appendix). The percentage reduction in power loss is $76.72 \%$ and the VSI is 0.9093 . Figure 3 represent the voltage profile for the IEEE 33 bus at different pf.

Table 1. Optimization result of IEEE 33 bus after DGs installation at different power factors

\begin{tabular}{|c|c|c|c|c|}
\hline \multirow[t]{2}{*}{ Item } & \multicolumn{4}{|c|}{$\mathrm{CP}$} \\
\hline & Without & Unity pf With DG & 0.95 Pf With DG & $0.85 \mathrm{pf}$ With DG \\
\hline Optimal DG & & $742.8868(14)$ & $749.8989(14)$ & $679.6554(14)$ \\
\hline Size (kW) (bus) & & $1260.0998(30)$ & $1199.3960(30)$ & $1182.6635(30)$ \\
\hline Total Size (KW) & & 2002.98 & 1949.29 & 1862.3 \\
\hline Power loss (kW) & 202.6771 & 86.345 & 47.1844 & 32.7278 \\
\hline$\%$ Reduction of power loss & & $57.39 \%$ & $76.72 \%$ & $83.85 \%$ \\
\hline VSI min (p.u.) & 0.6940 & $0.8858(18)$ & 0.9093 & 0.912 \\
\hline Minimum (p.u) (bus) & 0.9131 & $0.9703(18)$ & 0.9786 & $0.9793 \mathrm{pu}$ \\
\hline $\operatorname{TOC}(\$)$ & & 10360 & 9935.2 & 9442.5 \\
\hline
\end{tabular}

Table 2. Comparison optimization results of IEEE 33 bus after DGs installation at different power factors

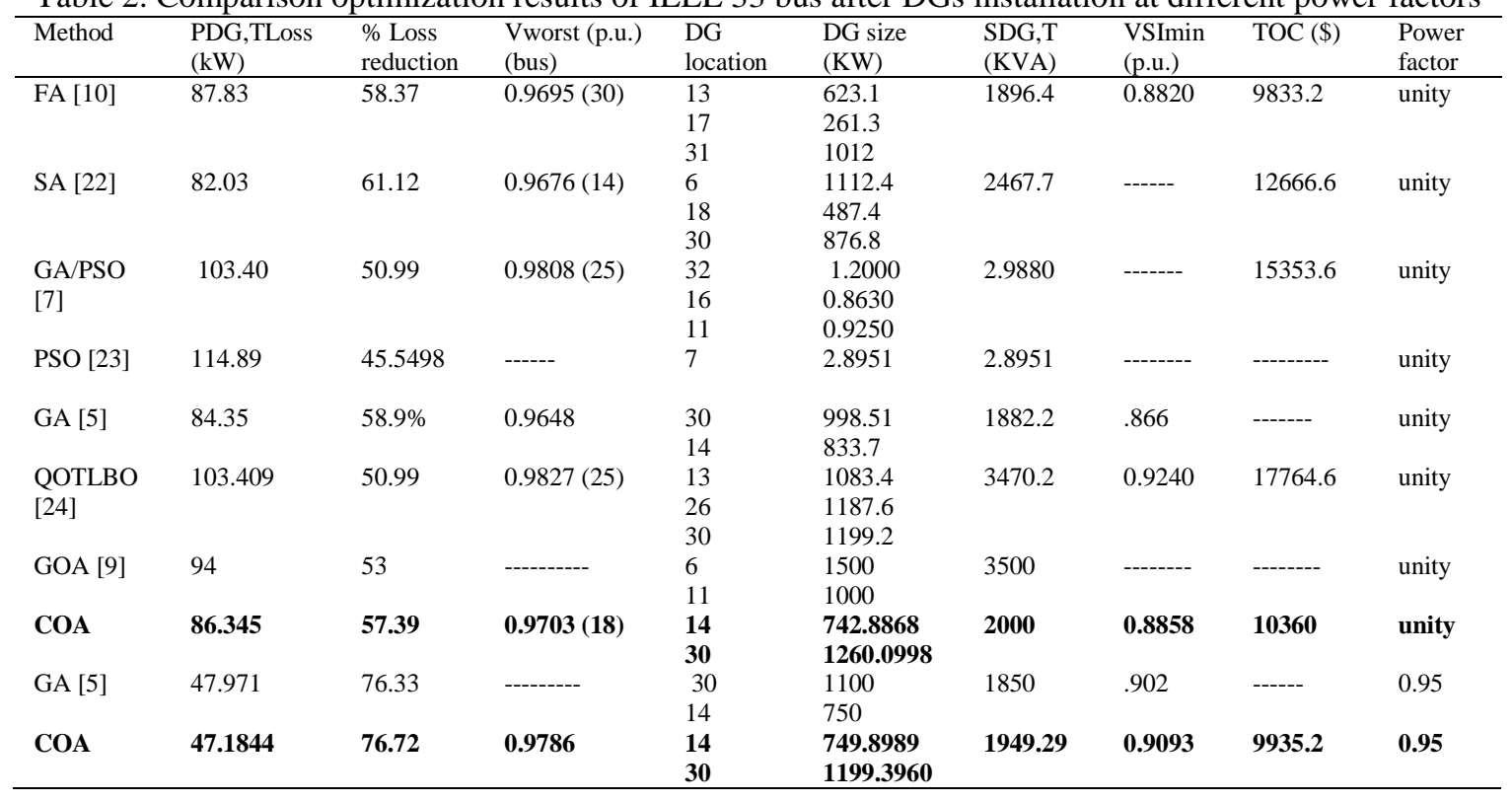




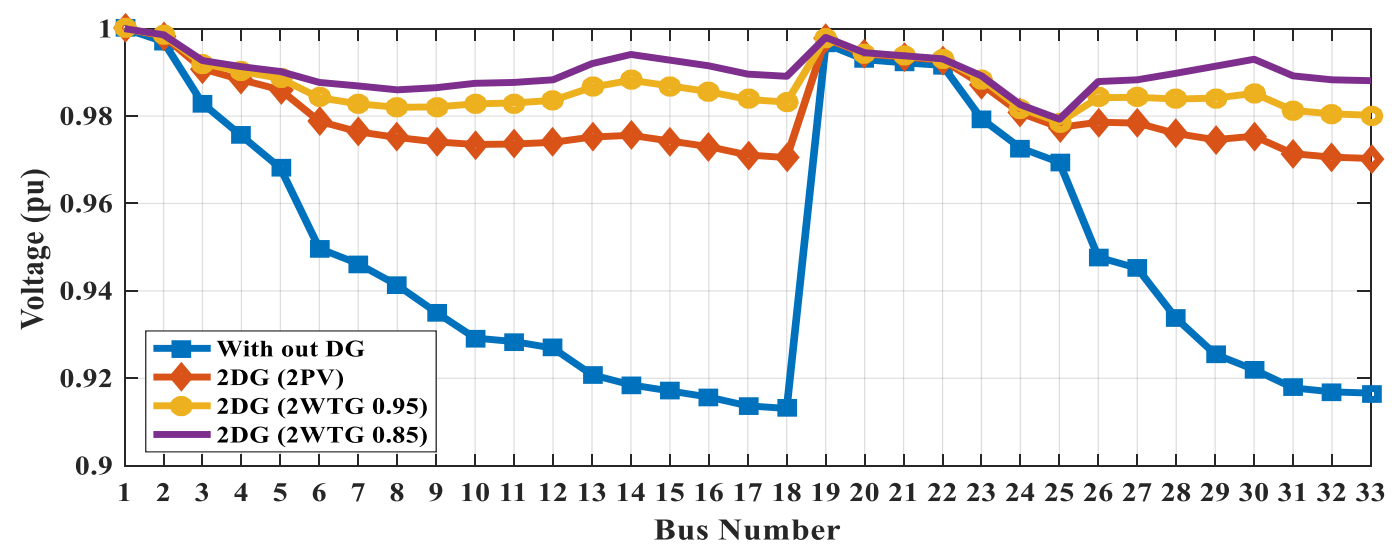

Figure 3. Voltage profile for 33-bus test system at different pf

\subsection{Optimization results for IEEE 69 bus}

The second test system is IEEE 69 bus that has a total load of $3.8 \mathrm{MW}$ and $2.69 \mathrm{MVAr}$ at $12.6 \mathrm{kV}$. Forward-backward sweep algorithm is used to calculate total power losses for the base case which is $225.0028 \mathrm{KW}$ with minimum voltage $0.9092 \mathrm{p} . \mathrm{u}$ [25]. Optimization and comparison results are tabulated in Tables 3 and 4. It is clear from the comparison that COA gives a good agreement in case of power loss reduction and VSI at unity power factor. Moreover, in case of $0.95 \mathrm{pf}$. COA gives better results than other algorithms for power loss reduction, VSI, and voltage profile improvement. Figure 4 show the voltage profile for IEEE 69 bus at different pf.

Table 3. Optimization result of IEEE 69 bus after DGs installation at different power factors

\begin{tabular}{ccccc}
\hline Item & \multicolumn{3}{c}{ CP } \\
\cline { 2 - 5 } & Without & Unity pf & 0.95 Pf & $0.85 P F$ \\
With DG & With DG & With DG \\
\hline Optimal DG & & $158.0401(25)$ & $365.4609(21)$ & $351.0718(21)$ \\
size(kW)(bus) & & $1745.1869(50)$ & $1806.2857(50)$ & $1654.0789(50)$ \\
Total Size (KW) & & 1903.227 & 2171.746 & 2005.1 \\
Power loss (kW) & 225.0028 & 77.5752 & 26.5529 & 11.3494 \\
\% Reduction of & & $65.5 \%$ & $88.1 \%$ & $94.95 \%$ \\
power loss & & & & .9532 \\
VSImin (p.u.) & $0.6823 \mathrm{pu}$ & $.9041(27)$ & 0.9884 & 0.9894 \\
Vminimum(p.u) & $0.9092 \mathrm{pu}$ & 0.9755 & $10965 \mathrm{e}$ & 10071 \\
TOC (\$) & & 9826.4 & & \\
\hline
\end{tabular}

Table 4. Comparison optimization results of IEEE 69 bus after installation DGs at different power factors

\begin{tabular}{|c|c|c|c|c|c|c|c|c|c|}
\hline Method & $\begin{array}{l}\text { PDG, } \\
\text { TLoss } \\
(\mathrm{kW})\end{array}$ & $\begin{array}{l}\% \text { Loss } \\
\text { reduction }\end{array}$ & $\begin{array}{l}\text { Vworst (p.u.) } \\
\text { (bus) }\end{array}$ & $\begin{array}{l}\text { DG } \\
\text { location }\end{array}$ & $\begin{array}{l}\text { DG } \\
(\mathrm{KW}\end{array}$ & $\begin{array}{l}\text { SDG,T } \\
(\mathrm{KVA})\end{array}$ & $\begin{array}{l}\text { VSI } \\
\min (\text { p.u.) }\end{array}$ & $\begin{array}{l}\text { TOC } \\
(\$)\end{array}$ & $\begin{array}{l}\text { Power } \\
\text { factor }\end{array}$ \\
\hline FA [10] & 74.43 & 66.90 & 0.9775 (61) & $\begin{array}{l}61 \\
64 \\
27\end{array}$ & $\begin{array}{l}1142 \\
542 \\
366\end{array}$ & 2050 & 0.9100 & 10547.7 & unity \\
\hline $\begin{array}{l}(\mathrm{BFOA}) \\
{[17]}\end{array}$ & 89.90 & 57.38 & 0.9705 (29) & $\begin{array}{l}14 \\
18 \\
32\end{array}$ & $\begin{array}{l}652.1 \\
198.4 \\
1067.2\end{array}$ & 1917.6 & ------ & 9948.1 & Unit \\
\hline GA [5] & 76.98 & 65.73 & ---------- & $\begin{array}{l}24 \\
62\end{array}$ & $\begin{array}{l}223 \\
1738\end{array}$ & 1961 & .9096 & ------ & unity \\
\hline $\begin{array}{l}\text { QOTLBO } \\
{[24]}\end{array}$ & 80.58 & 64.14 & $0.9945(65)$ & $\begin{array}{l}15 \\
61 \\
63\end{array}$ & $\begin{array}{l}929.7 \\
1075.2 \\
992.5\end{array}$ & 2960.6 & 0.9585 & 15125.3 & unity \\
\hline COA & 77.5752 & 65.5 & 0.9755 & $\begin{array}{l}25 \\
50\end{array}$ & $\begin{array}{l}158.0401 \\
1745.1869\end{array}$ & 1903.227 & .9041 & 9826.4 & unity \\
\hline GA [5] & 29.47 & 77.9 & ----------- & $\begin{array}{l}61 \\
23\end{array}$ & $\begin{array}{l}1804 \\
330\end{array}$ & 2134 & .9389 & --------- & 0.95 \\
\hline COA & 26.5529 & 88.1 & 0.9786 & $\begin{array}{l}21 \\
50\end{array}$ & $\begin{array}{l}365.4609 \\
1806.2857\end{array}$ & 2171.746 & 0.9884 & 10965 & 0.95 \\
\hline
\end{tabular}




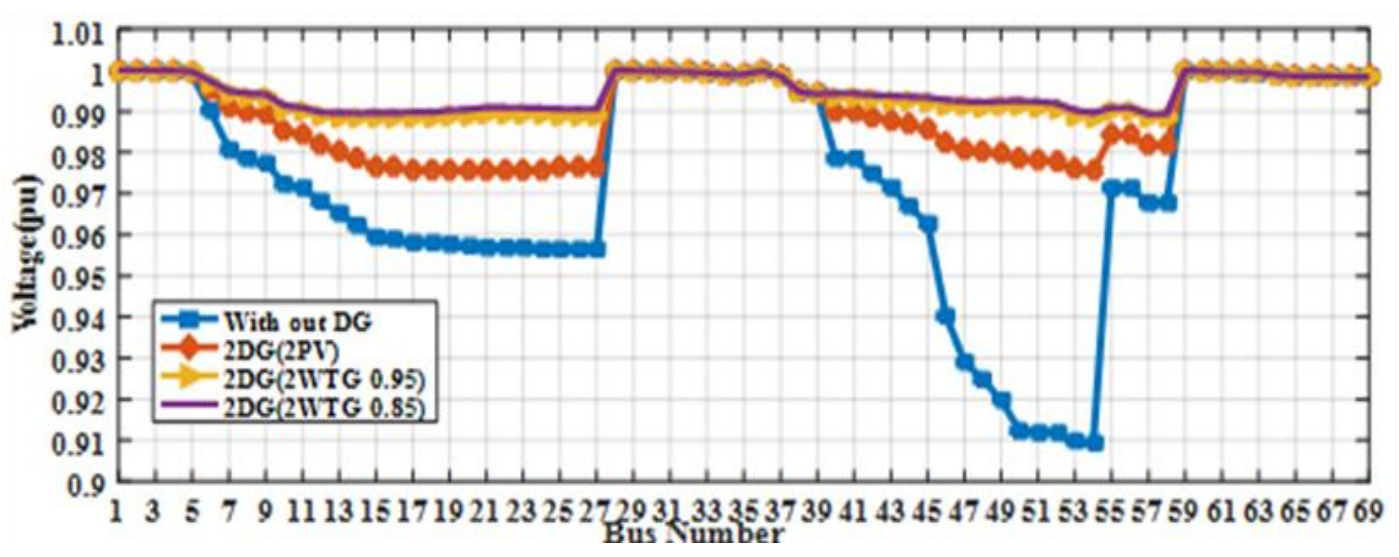

Figure 4. Voltage profile for IEEE 69 bus at different pf

\section{CONCLUSION}

This paper introduces implementation of new optimization algorithm (COA) to obtain optimum size and placement of RDGs that achieve increasing percentage of power loss reduction, voltage profile and voltage stability of all buses of the DN enhancement. the proposed algorithm is implemented for two test systems IEEE 33 and 69 bus RDS with constant load power at different power factors. DGs operating at unity, 0.95 and 0.85 power factor. The simulation result obtained by COA was compared with other popular algorithms FA, BFOA, and QOTLBO, GA. The proposed algorithm is extremely accurate for evaluating an optimal solution for location and size of DGs that give more power losses reduction and better result in improving voltage profile and VSI when compared with other algorithms.

\section{REFERENCES}

[1] G. Namachivayam, et al., "Reconfiguration and capacitor placement of radial distribution systems by modifier flower pollination algorithm," Electrical power components and systes, vol. 44, no. 13, pp. 1-11, 2016.

[2] Akorede, M. F., et al., "A review of strategies for optimal placement of distributed generation in power distribution systems," Research Journal of Applied Sciences, vol. 5, no. 2, pp. 137-145, 2010.

[3] G. R. Prudhvi Kumar, D. Sattianadan, K. Vijayakumar, "A survey on power management strategies of hybrid energy systems in microgrid," International Journal of Electrical and Computer Engineering (IJECE), vol. 10, no. 2, pp. 1667-1673, 2020.

[4] Mendez, V. H., et al., "Impact of distributed generation on distribution investment deferral," International Journal of Electrical Power \& Energy Systems, vol. 28, no. 2, pp. 244-252, 2006.

[5] Hassan, A. A., et al., "Hybrid genetic multi objective/fuzzy algorithm for optimal sizing and allocation of renewable DG systems,” International Transactions on Electrical Energy Systems, vol. 26, no. 12, pp. 2588-2617, 2016.

[6] M. M. Aman, et al., "A new approach for optimum DG placement and sizing based on voltage stability maximization and minimization of power losses," Energy Conversion and Management, vol. 70, pp. 202-210, 2013.

[7] M. H. Moradi., et al., "A combination of genetic algorithm and particle swarm optimization for optimal DG location and sizing in distribution systems," International Journal of Electrical Power \& Energy Systems, vol. 34, no. 1, pp. 66-74, 2012.

[8] M. H. Moradi., et al., "Multi-objective PFDE algorithm for solving the optimal siting and sizing problem of multiple DG sources," International Journal of Electrical Power \& Energy Systems, vol. 56, pp. 117-126, 2014.

[9] K. Vinothkumar, et al., "Distributed generation planning: a new approach based on goal programming," Electric Power Components and Systems, vol. 38, no. 5, pp. 260-274, 2012.

[10] Sureshkumar S., et al., "Optimal allocation of multiple distributed generators in distribution system using firefly algorithm," Journal of Electrical Engineering, vol. 17, pp. 1-12, 2017.

[11] Payman Dehghanian, et al., "Optimal siting of DG units in power systems from a probabilistic multi-objective optimization perspective," International Journal of Electrical Power \& Energy Systems, vol. 51, pp. 14-26, 2013.

[12] Taher Niknam, et al., "A modified honey bee mating optimization algorithm for multi-objective placement of renewable energy resources," Applied Energy, vol. 88, no. 12, pp. 4817-4830, 2011.

[13] D. Das, "Optimal placement of capacitors in radial distribution system using a Fuzzy-GA method," International Journal of Electrical Power \& Energy Systems, vol. 30, no. 6-7, pp. 361-367, 2008.

[14] Jen-HaoTeng, et al., "Adirect approach for distribution system load flow solutions," IEEE Transactions on Power Delivery, vol. 18, no. 3, pp. 882-887, 2003.

[15] Singh, D., "Multiobjective optimization for DG planning with load models," IEEE Transactions on Power Systems, vol. 24, no. 1, pp. 427-436, 2009. 
[16] Chakravorty, M., et al., "Voltage stability analysis of radial distribution networks," International Journal of Electrical Power \& Energy Systems, vol. 23, pp. 129-135, 2001.

[17] Mohamed Imran A., et al., "Optimal size and siting of multiple distributed generators indistribution system using bacterial foraging optimization," Swarm and Evolutionary Computation, vol. 15, pp. 58-65, 2014.

[18] M. Bekoff, et al., "Canis latrans," Mammalian Species, vol. 1, no. 79, pp. 1-9, 1977.

[19] W. C. Pitt, et al., "An individual-based model of canid populations: Modelling territoriality and social structure," Ecological Modelling, vol. 166, no. 1-2, pp. 109-121, 2003.

[20] Juliano Pierezan, et al., "Coyote Optimization Algorithm: A new metaheuristic for global optimization problems," 2018 IEEE Congress on Evolutionary Computation (CEC), Rio de Janeiro, pp. 1-8, 2018.

[21] M. E. Baran, et al., "Network reconfiguration in distribution systems for loss reduction and load balancing," IEEE Transaction on Power Delivery, vol. 4, no. 2, pp. 1401-1407, 1989.

[22] Satish Kumar Injeti, et al., "Anovel approach to identify optimal access point and capacity of multiple DGs in asmall, medium and large scale radial distribution systems," International Journal of Electrical Power \& Energy Systems, vol. 45, no. 1, pp. 142-151, 2013.

[23] M. M. Aman, G. B. Jamson, H. Mokhlis and A. H. A. Bakar, "A new approach for optimum DG placement and sizing based on voltage stability maximization and minimization of power losses," Energy Conversion and Management, vol. 70, no. 202-210, 2013.

[24] Sultana, S., et al., "Multi-objective quasi-oppositional teaching learning based optimization for optimal location of distributed generator in radial distribution systems," International Journal of Electrical Power \& Energy Systems, vol. 63 , pp. 534-545, 2014.

[25] M.E. Baran, et al., "Optimum sizing of capacitor placed on radial distribution systems," IEEE Transaction on Power Delivery, vol. 4, no. 1, pp.735-743, 1989.

\section{BIOGRAPHIES OF AUTHORS}

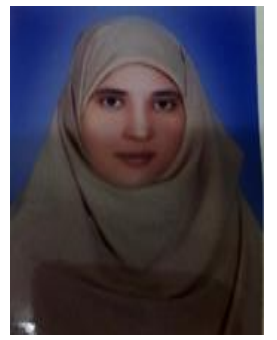

E. M. Abdallah received her B.Sc. in electrical power and machines from the Faculty of Engineering, Al-Azhar university in 2012. She awarded her M.Sc. in electrical power and machines from the Faculty of Engineering, Al-Azhar university in 2016. Currently, she is a lecturer Assistant at electrical power and machines dept., Faculty of Engineering, Al-Azhar University. Her research interests include renewable energy systems, power systems, optimization and control of smart grid.

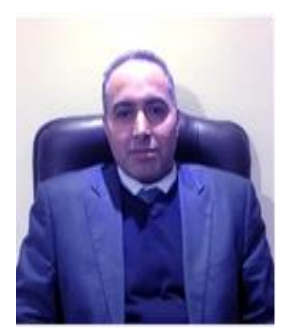

M. I. ELsayed received his B.Sc. in electrical power and machines from the Faculty of Engineering, Al-Azhar university in 1997. He awarded his M.Sc, PhD, ASS Prof and Prof. In electrical power and machines from the Faculty of Engineering, Al-Azhar university in 2003, 2007, 2012 and 2017, respectively. Currently, He is Vice Dean of Faculty of Engineering (femal), Al-Azhar university. His research interests control of power systema and reliability and stability of electric power systems.

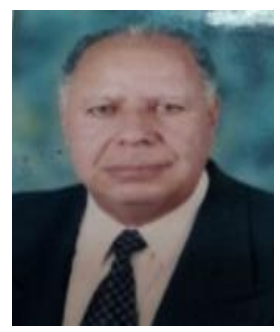

M. M. ELgazzer received his B.Sc. in electrical power and machines from the Faculty of Engineering, Al-Azhar university in 1971. He awarded his M.Sc, PhD, and ASS Prof. in electrical power and machines from the Faculty of Engineering, Al-Azhar university in 1976, 1983, 1988 and 1993, respectively. His research interests control of power system and reliability and stability of electric power systems.

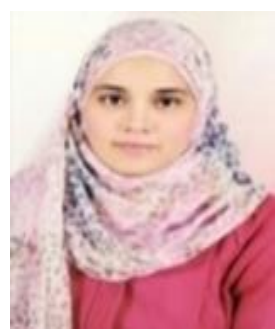

Amal A. Hassan received her B.Sc. in electrical power and machines from the Faculty of Engineering, Cairo University in 2003. She awarded her M.Sc. and Ph.D. in electrical power and machines from the Faculty of Engineering, Cairo University in 2009, and 2016, respectively. Currently, she is a researcher in Photovoltaic Cells Dept., Electronics Research Institute (ERI), and Cairo, Egypt. Her research interests include grid-connected PV systems, smart power grid, optimization, and control of distributed generation based on renewable energy and microgrid. 